\title{
Quantitation of Nitrotyrosine Levels in Lung Sections of Patients and Animals with Acute Lung Injury
}

\author{
Imad Y. Haddad, ${ }^{\star}$ Gyorgy Pataki, ${ }^{\ddagger}$ Ping Hu, ${ }^{\ddagger}$ Carlos Galliani, ${ }^{\S}$ Joseph S. Beckman, ${ }^{\ddagger}$ and Sadis Matalon ${ }^{\star \star \|}$ \\ Departments of * Pediatrics, ${ }^{\ddagger}$ Anesthesiology, ${ }^{\S}$ Pathology, and "Physiology and Biophysics, University of Alabama at Birmingham, \\ Birmingham, Alabama 35233-6810
}

\begin{abstract}
Activated alveolar macrophages and epithelial type II cells release both nitric oxide and superoxide which react at near diffusion-limited rate $\left(6.7 \times 10^{9} \mathrm{M}^{-1} \mathrm{~s}^{-1}\right)$ to form peroxynitrite, a potent oxidant capable of damaging the alveolar epithelium and pulmonary surfactant. Peroxynitrite, but not nitric oxide or superoxide, readily nitrates phenolic rings including tyrosine. We quantified the presence of nitrotyrosine in the lungs of patients with the adult respiratory distress syndrome (ARDS) and in the lungs of rats exposed to hyperoxia $\left(100 \% \mathrm{O}_{2}\right.$ for $60 \mathrm{~h}$ ) using quantitative immunofluorescence. Fresh frozen or paraffin-embedded lung sections were incubated with a polyclonal antibody to nitrotyrosine, followed by goat anti-rabbit IgG coupled to rhodamine. Sections from patients with ARDS $(n=5)$, or from rats exposed to hyperoxia $(n=4)$, exhibited a twofold increase of specific binding over controls. This binding was blocked by the addition of an excess amount of nitrotyrosine and was absent when the nitrotyrosine antibody was replaced with nonimmune IgG. In additional experiments we demonstrated nitrotyrosine formation in rat lung sections incubated in vitro with peroxynitrite, but not nitric oxide or reactive oxygen species. These data suggest that toxic levels of peroxynitrite may be formed in the lungs of patients with acute lung injury. (J. Clin. Invest. 1994. 94:2407-2413.) Key words: nitric oxide $\cdot$ peroxynitrite $\cdot$ reactive oxygen species - quantitative immunofluorescence - hyperoxia • adult respiratory distress syndrome
\end{abstract}

\section{Introduction}

The free radical nitric oxide $(\bullet \mathrm{NO})^{1}$ is the major form of the endothelial-derived relaxing factor that is enzymatically synthesized from arginine oxidation by a NADPH-dependent nitric oxide synthase. Nitric oxide causes smooth muscle relaxation by activating soluble guanylate cyclase, and inhibits platelet

Address correspondence to Sadis Matalon, PhD, Department of Anesthesiology, University of Alabama at Birmingham, 619 South 19th Street, Birmingham, AL 35233-6810. 1994.

Received for publication 6 May 1994 and in revised form 29 July

1. Abbreviations used in this paper: ARDS, adult respiratory distress syndrome; $\bullet N O$, nitric oxide; NTAb, polyclonal antibody against nitrotyrosine; SNAP, $S$-nitroso- $N$-acetylpenicillamine.

J. Clin. Invest.

(C) The American Society for Clinical Investigation, Inc. 0021-9738/94/12/2407/07 $\$ 2.00$

Volume 94, December 1994, 2407-2413 aggregation and adhesion to endothelium by increasing cGMP. Because of the vasorelaxant properties of $\bullet N O$ and its rapid inactivation in the blood by its reaction with hemoglobin, $\bullet N O$ inhalation has been advocated as a means of selectively reducing pulmonary hypertension and improving ventilation/perfusion mismatching in patients with idiopathic pulmonary hypertension and adult respiratory distress syndrome $(1,2)$.

In spite of its therapeutic potential, $\cdot \mathrm{NO}$ has significant cytotoxicity. In high concentrations, $\bullet \mathrm{NO}$ may inactivate critical enzymes ( such as mitochondrial aconitase, NADH:ubiquinone oxidoreductase) by interacting with iron-sulfur centers to form iron-sulfur-nitrosyl derivatives, and inhibit both DNA and protein synthesis $(3,4)$. Also, since $\cdot N O$ is a free radical, it can undergo a radical-radical reaction with superoxide at near diffusion-limited rates to yield peroxynitrite, a potent oxidizing agent known to initiate lipid peroxidation in biological membranes, hydroxylation and nitration of aromatic amino acid residues, and sulfhydryl oxidation of proteins $(5,6)$. Furthermore, peroxynitrite may decompose homolytically to yield nitrogen dioxide, and species with hydroxyl radical-like reactivity, without the need of metal catalysis (7).

Stimulation by cytokines or lipopolysaccharide causes alveolar macrophages, lung epithelial, endothelial, and interstitial cells to produce large amounts of $\bullet \mathrm{NO}$ and superoxide for prolonged periods of time, creating foci for the intense and localized production of peroxynitrite and its toxic intermediates, in close proximity to all components of the blood gas barrier. Our previous results indicate that peroxynitrite, or agents that generate $\bullet \mathrm{NO}$ and superoxide simultaneously, damage alveolar type II cells and specific surfactant apoproteins to a much higher extent than supraphysiological concentrations of reactive oxygen species (8-10). These findings indicate the cytotoxic potential of peroxynitrite to the mamalian alveolar epithelium. However, currently, there is controversy as to whether peroxynitrite is being formed by mammalian lung cells in vivo.

One way to demonstrate peroxynitrite formation in vivo is to detect the presence of stable by-products of its reaction with various biological compounds. 3-nitro-tyrosine, the product of the addition of a nitro group $\left(\mathrm{NO}_{2}\right)$ to the ortho position of the hydroxyl group of tyrosine, is such a stable compound. Herein we report the presence of 3-nitro-tyrosine (nitrotyrosine) in (a) the lungs of pediatric patients with adult respiratory distress syndrome (ARDS), and $(b)$ in the lungs of rats exposed $100 \%$ $\mathrm{O}_{2}$ for $60 \mathrm{~h}$. This exposure protocol has been shown to damage both the pulmonary capillary endothelium and the alveolar epithelium and results in noncardiogenic pulmonary edema (11). Thus, the pathophysiology of hyperoxic injury to the mammalian lung resembles closely the pulmonary manifestations of human adult respiratory distress syndrome. The presence of nitrotyrosine was demonstrated by incubating tissue sections, obtained from the lungs of both patients and animals, with a polyclonal antibody to nitrotyrosine (12), followed by a sec- 
Table I. Characteristics of ARDS Patients

\begin{tabular}{|c|c|c|c|c|}
\hline Patient & Age/sex & Diagnosis & $\begin{array}{l}\text { Clinical } \\
\text { phase }\end{array}$ & $\begin{array}{c}\text { Tissue prep./lung } \\
\text { pathology }\end{array}$ \\
\hline $\begin{array}{l}1 \text { C.D. } \\
\text { autopsy }\end{array}$ & $14 \mathrm{yr} / \mathrm{F}$ & Lymphoma & Late & $\begin{array}{r}\text { f.f.\&par./fibro } \\
\text { proliferative }\end{array}$ \\
\hline $\begin{array}{l}2 \text { A.P. } \\
\text { autopsy }\end{array}$ & $9 \mathrm{yr} / \mathrm{F}$ & Sepsis & ARF & $\begin{array}{l}\text { par./cellular } \\
\text { proliferative }\end{array}$ \\
\hline $\begin{array}{l}3 \text { A.R. } \\
\text { autopsy }\end{array}$ & $3 \mathrm{mo} / \mathrm{M}$ & Sepsis & cARF & par./exudative \\
\hline $\begin{array}{l}4 \text { T.H. } \\
\text { autopsy }\end{array}$ & $23 \mathrm{mo} / \mathrm{F}$ & $\begin{array}{l}\text { Near } \\
\quad \text { drowning }\end{array}$ & ARF & $\begin{array}{l}\text { par./cellular } \\
\text { proliferative }\end{array}$ \\
\hline $\begin{array}{l}5 \text { J.J. } \\
\text { biopsy }\end{array}$ & $19 \mathrm{mo} / \mathrm{M}$ & $\begin{array}{r}\text { Upper airway } \\
\text { obstruction }\end{array}$ & Late & $\begin{array}{l}\text { par./fibro } \\
\text { proliferative }\end{array}$ \\
\hline
\end{tabular}

M, male; F, female; ARF, acute respiratory failure; f.f., fresh frozen; par., paraffin embedded.

ondary fluorescently labeled antibody, and quantifying the degree of specific fluorescence. We also show evidence indicating that nitrotyrosine formation is caused by peroxynitrite, and not nitric oxide or reactive oxygen species generated by xanthine oxidase plus $\mathrm{Fe}^{3+}$ EDTA. Coupled with our previous measurements these results indicate the presence of significant amounts of nitrotyrosine in lungs with ARDS, and establish that peroxynitrite, or its reactive by-products, may play a significant role in the pathology of ARDS.

\section{Methods}

Human lung sections. Lung tissue samples from five pediatric patients with clinical diagnosis of ARDS (age 3 mo to $14 \mathrm{yr}$ ), triggered by a variety of predisposing factors, were obtained either during autopsy ( $n$ $=4$ ) or during surgical biopsy ( $n=1$; to rule out infection). Lung tissue samples were also obtained during autopsy $(n=4)$ or surgical biopsy $(n=1)$ from the lungs of five non-ARDS patients without histologic evidence of pulmonary inflammation. Characteristics of these patients and their primary diagnosis are shown in Tables I and II. Whenever possible, pieces of lung tissue were obtained specifically for this study. These tissues were immediately frozen at $-80^{\circ} \mathrm{C}$ (non-ARDS $=4$, ARDS $=1$ ). Alternatively, lung sections fixed in $10 \%$ buffered formalin for 24-48 $\mathrm{h}$ and embedded in paraffin were used (non-ARDS $=1$, ARDS $=5)$. Cryo-sections (4-6 $\mu \mathrm{m})$ were cut from tissue blocks using a cryostat II (Tissue-Tek II model 4553; Miles Inc., Kankakee, IL) at $-30^{\circ} \mathrm{C}$ and mounted on glass slides.

Exposure of rats to hyperoxia. Adult male Sprague-Dawley rats $(275-350 \mathrm{~g})$ were exposed to $100 \% \mathrm{O}_{2}$ for $60 \mathrm{~h}$ inside specially designed environmental chambers constructed from Lucite, with a metal top to facilitate heat transfer. Throughout the exposure period, the chambers were housed in a room kept at constant temperature $\left(21^{\circ} \mathrm{C}\right)$. The construction of the chambers allowed for the administration of food and water to the rats and the removal of animal waste through airlocks without altering the gas composition of their environment. The chambers were continuously flushed with $10 \mathrm{liter} / \mathrm{min}$ of $100 \% \mathrm{O}_{2}$ (Airco, Birmingham, AL). The oxygen concentration in the chamber, monitored periodically with an oxygen analyzer (model 5120; Ohmeda, Englewood, $\mathrm{CO}$ ), was always higher than $97 \%$. In all experiments the temperature in the chamber was between $23-24^{\circ} \mathrm{C}$.

At the end of the 60-h exposure period, the rats were removed from the chambers, and anesthetized by an intraperitoneal injection of sodium pentothal $(50 \mathrm{mg} / \mathrm{kg})$. The trachea was exposed and a plastic catheter was inserted so its tip was just above the carina. The catheter was occluded and the lungs were allowed to collapse by absorption atelecta-
Table II. Characteristics of Non-ARDS Patients

\begin{tabular}{|c|c|c|c|}
\hline Patient & Age/sex & Diagnosis & $\begin{array}{l}\text { Tissue prep./lung } \\
\text { pathology }\end{array}$ \\
\hline $\begin{array}{l}6 \text { T.H. } \\
\text { autopsy }\end{array}$ & $12 \mathrm{yr} / \mathrm{F}$ & MD/heart failure & f.f./Lung edema \\
\hline $\begin{array}{l}7 \text { C.M. } \\
\text { autopsy }\end{array}$ & $2 \mathrm{wk} / \mathrm{M}$ & IVH & f.f./Normal \\
\hline $\begin{array}{l}8 \text { C.H. } \\
\text { autopsy }\end{array}$ & $1 \mathrm{mo} / \mathrm{F}$ & Sepsis & f.f./Lung edema \\
\hline $\begin{array}{l}9 \text { M.C. } \\
\text { autopsy }\end{array}$ & $14 \mathrm{yr} / \mathrm{M}$ & $\begin{array}{l}\text { Marfan's/cardiac } \\
\text { tamponade }\end{array}$ & f.f./Normal \\
\hline $\begin{array}{l}10 \text { J.J. } \\
\text { biopsy }\end{array}$ & $3 \mathrm{yr} / \mathrm{M}$ & $\begin{array}{l}\text { Upper airway } \\
\text { obstruction }\end{array}$ & $\begin{array}{l}\text { par./consistent } \\
\text { with healed } \\
\text { BPD }\end{array}$ \\
\hline
\end{tabular}

M, male; F, female; f.f., fresh frozen; par., paraffin; $M D$, muscular dystrophy; IVH, intraventricular hemorrhage; BPD, bronchopulmonary dysplasia.

sis. The chest was then opened, and $10 \mathrm{ml}$ of Tissue-Tek ornithine carbamyl transferase compound was instilled into the lungs via a syringe. The lungs and heart were removed from the thoracic cavity en bloc, and immediately frozen at $-20^{\circ} \mathrm{C}$. Cryo-sections $(6 \mu \mathrm{m})$ were cut at $-30^{\circ} \mathrm{C}$ and mounted on glass slides.

Immunofluorescent measurements. Paraffin-embedded sections were deparaffinized by dipping in successive solutions containing alcohol and xylene. These sections, along with the fresh frozen ones, were then fixed and permeabilized by immersion in pure methanol at $-20^{\circ} \mathrm{C}$ for 7 min, followed by immersion in $1 \%$ cold $\left(4^{\circ} \mathrm{C}\right)$ bovine serum albumin in PBS for $3 \mathrm{~h}$ to block nonantigenic sites. They were then incubated with a polyclonal antibody raised against nitrotyrosine (NTAb; 1:200 dilution), followed by a secondary antibody, goat anti-rabbit IgG conjugated to rhodamine (1:300 dilution). The NTAb was raised in rabbits by injecting them with peroxynitrite treated keyhole limpet hemocyanin (KLH; Pierce, Rockford, IL), in the presence of $\mathrm{Fe}^{3+}$ EDTA (12), which should drive the peroxynitrite modification towards nitration of the 3- position of the tyrosine residues, rather than hydroxylation. Phenylalanine is poorly nitrated by peroxynitrite, because it lacks the activating hydroxyl group in its aromatic ring.

In control measurements, tissues were incubated with NTAb in the presence of $10 \mathrm{mM}$ nitrotyrosine, or with a similar amount of nonimmune anti-rabbit IgG. Tissues were then washed with cold PBS to remove unbound antibody, overlaid with a drop of glycerol/PBS (9:1) mounting medium containing $0.01 \%$ phenylene diamine to prevent fluorescence bleaching, covered with a coverslip and sealed with Cytoseal 60 Mounting Medium (Stephens Scientific, Denville, NJ). The slides were stored at $-20^{\circ} \mathrm{C}$ until examined.

Lung sections were viewed with a AusJena Sedival inverted microscope (Jenoptik Jena GmbH, Germany) equipped with $50 \times$ planachromat objective, Hoffman optics, and fluorescence capability with standard fluorescein ( $485 \pm 20 \mathrm{~nm}$ excitation; $520-560 \mathrm{~nm}$ emission) and rhodamine ( $546 \pm 10 \mathrm{~nm}$ excitation; $590 \mathrm{~nm}$ emission) filters. For each slide, at least four images were selected randomly, while viewing the slides under light microscopy and the corresponding fluorescent images were captured by a Photometrics Series 200 cooled charged-coupled device (CCD) camera system (Photometrics, Tucson, AZ) connected to Macintosh IIci computer. Video images were digitized into two dimensional arrays of picture elements (pixels). Each pixel is a square with a width of $0.21 \mu \mathrm{m}$. In each field of view ( 500 magnification), there are 221,184 pixels corresponding to $9754 \mu \mathrm{m}^{2}$ (23 pixels $/ \mu \mathrm{m}^{2}$ ). Each pixel was assigned an intensity value ranging from 0 (black) to 16384 (white). Alveolar structures in each image were outlined using digital imaging techniques. The intensity value of each pixel within the outlined area 

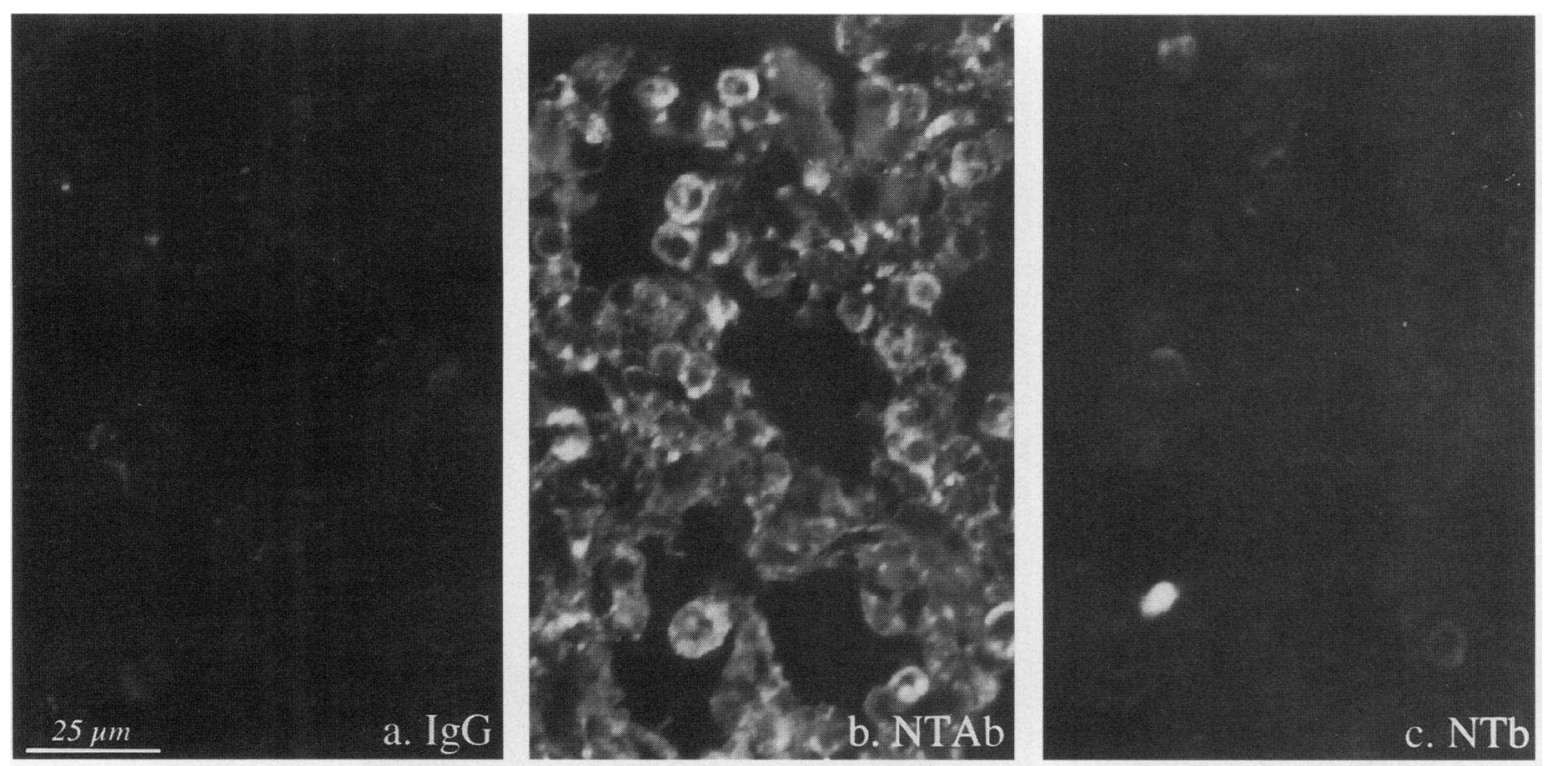

Figure 1. Epifluorescence images of paraffin-embedded, semi-thin (4-6 $\mu \mathrm{m}$ ) lung sections from a patient (A.P.) with ARDS, incubated with ( $a$ ) nonspecific IgG (IgG, left); (b) the polyclonal antibody to nitrotyrosine (NTAb) (NTAb; middle), or (c) the NTAb in the presence of 10 mM nitrotyrosine $(\mathrm{NTb} ;$ right $)$. All sections were then incubated with a secondary antibody, goat anti-rabbit IgG coupled to rhodamine. All pictures were obtained with identical camera and computer settings. Significantly higher specific immunostaining (white areas) was noted with lung sections incubated with the NTAb (mean pixel intensity $=155$ ) compared to sections stained with nonspecific IgG (mean intensity $=90$ ), or the NTAb in the presence of $10 \mathrm{mM}$ nitrotyrosine (mean intensity $=96$ ). Results were reproduced using either formalin-fixed, or fresh-frozen sections from five patients with ARDS.

was measured and the mean intensity value was calculated using the IPLab Spectrum 2.2.1 software (Signal Analytics Co., Vienna, VA). Background fluorescence was digitally subtracted, as previously described (13).

In vitro exposure of rat lung sections to oxidants. To determine which oxidant is capable of nitrating lung tyrosine residues, lung sections from control rats, prepared as described above, were immersed in a $10 \mathrm{mM}$ Hepes solution $(150 \mathrm{mM} \mathrm{NaCl}, 5 \mathrm{mM} \mathrm{KCl}, 2 \mathrm{mM} \mathrm{CaCl}$, $1.2 \mathrm{mM} \mathrm{MgCl}{ }_{2} ; \mathrm{pH} \mathrm{7.4)}$. They were then incubated for $2 \mathrm{~h}$ at $37^{\circ} \mathrm{C}$ with $(a)$ a bolus of peroxynitrite $(1 \mathrm{mM})$, synthesized from sodium nitrite and acidified hydrogen peroxide as previously described (7); (b) $S$-nitroso- $N$-acetylpenicillamine (SNAP; $100 \mu \mathrm{M}$ plus $100 \mu \mathrm{M} \mathrm{L-}$ cysteine), which generates a mean $\cdot N O$ concentration of about $1 \mu \mathrm{M}$ over the exposure period (10; equivalent to $25 \mathrm{ppm}$ of $\bullet \mathrm{NO}$ in the gas phase ); or (c) xanthine oxidase ( $10 \mathrm{mU} / \mathrm{ml})$ plus pterin $(200 \mu \mathrm{M})$ in the presence of $100 \mu \mathrm{M} \mathrm{Fe}^{3+}$ EDTA, which generate superoxide, hydrogen peroxide, and hydroxyl radicals. Xanthine oxidase was equilibrated with $10 \mathrm{mM}$ Hepes buffer ( $\mathrm{pH} 7.4$ ). Its activity was determined spectrophotometrically by measuring the rate of urate production at $295 \mathrm{~nm}$ in 500 $\mu \mathrm{M}$ xanthine $\left(\epsilon_{\mathrm{M}}=1.1 \times 10^{-4} \mathrm{M}^{-1} \mathrm{~cm}^{-1}\right)$.

Statistical analysis. All results are expressed as means \pm 1 SEM. Statistical differences among group means were determined using one way analysis of variance and the Bonferroni modification of the $t$ test.

\section{Results}

Paraffin-embedded lung tissue sections from a patient with sepsis-induced ARDS (A.P., see Table I) exhibited significant specific immunostaining with the polyclonal antibody to nitrotyrosine (Fig. 1). Immunostaining was reduced to control levels when lung sections were incubated with the NTAb in the presence of an excess amount of antigen ( $10 \mathrm{mM}$ nitrotyrosine), or when the primary antibody was replaced with an equal amount of nonimmune IgG. Fig. 2 shows the relative distribution of the mean fluorescence intensity among the different lung fields examined from another ARDS patient (C.D.). Staining was continuous and uniform around the blood gas barrier. Mean pixel intensity in fresh frozen sections from this patient incubated with the NTAb was $37 \%$ higher than the corresponding value in formalin-fixed sections, obtained at the same time and processed under identical conditions. Based on these findings, since a larger proportion of lung sections from non-ARDS patients was fresh frozen, increased immunofluorescence should be expected, as compared with the ARDS group; the opposite was observed (see below).

Fig. 3 shows a fluorescent image of a frozen lung section from a subject that died without clinical or pathologic evidence of acute lung inflammation (patient T.H.). No significant difference was detected between the recorded fluorescence values

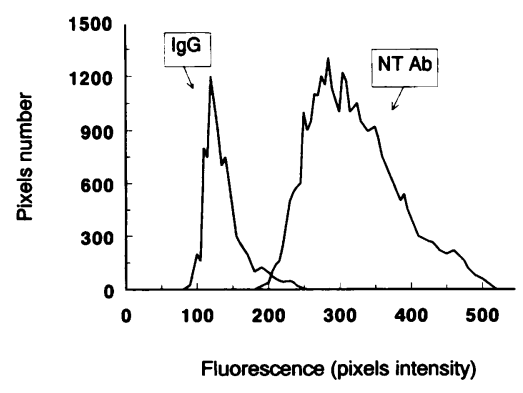

Figure 2. Contour plot of fluorescent intensity in a lung section of an ARDS patient (C.D.), incubated with nonspecific IgG or an equivalent amount of the polyclonal antibody to nitrotyrosine (NTAb), followed by the secondary antibody, goat antirabbit IgG coupled to rhodamine. The $\mathrm{x}$ axis

represents the intensity value for the number of pixels shown on the $y$ axis. This quantitative representation of the pattern of fluorescence confirms that staining was uniform. 


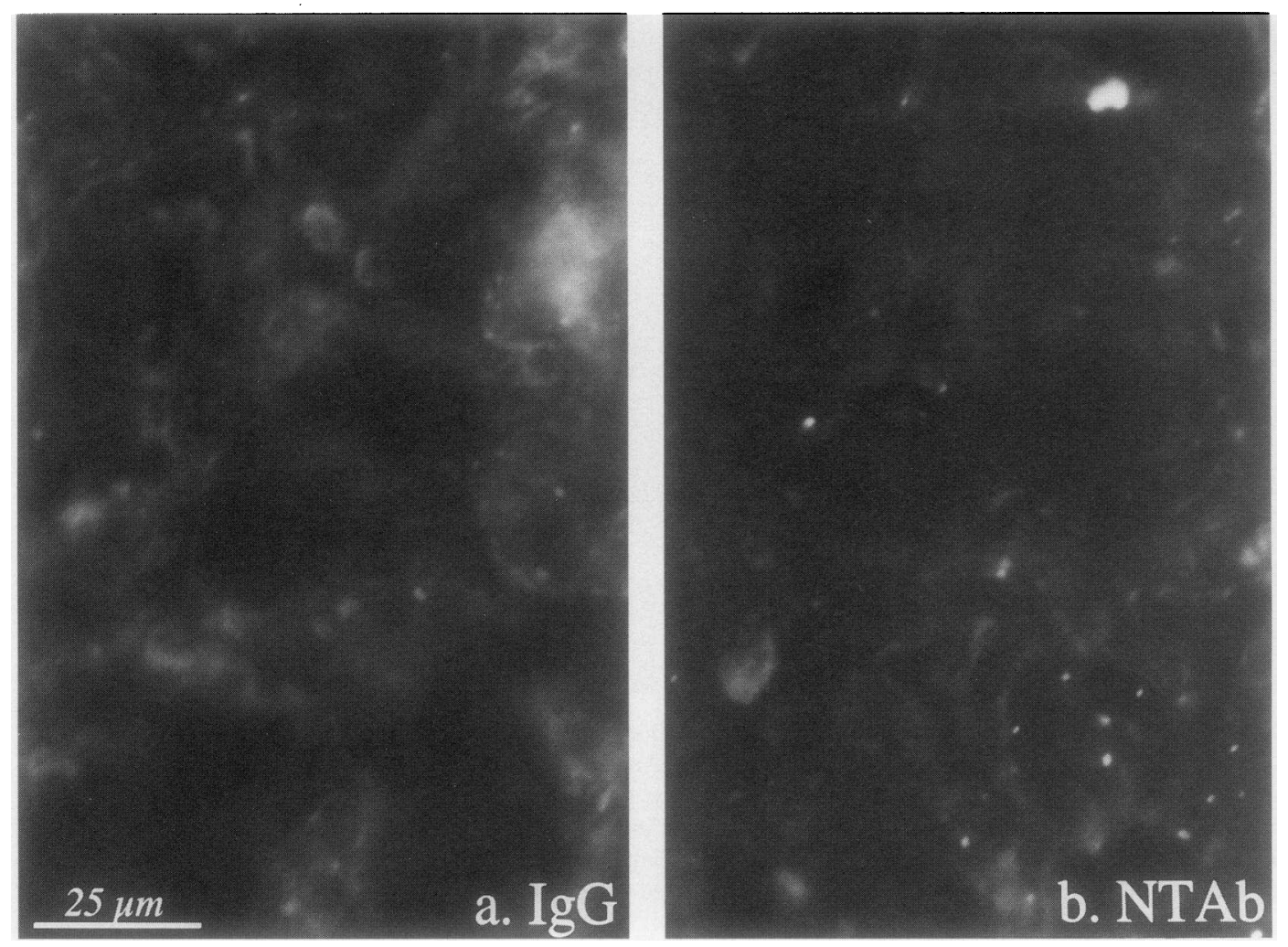

Figure 3. Epifluorescence images of fresh-frozen, semi-thin (4-6 $\mu \mathrm{m})$ lung sections from a patient, who did not show evidence of acute lung injury at death (T.H.). Sections were incubated with $(a)$ nonspecific IgG (IgG; left) or $(b)$ the polyclonal antibody to nitrotyrosine (NTAb) (NTAb; right). All sections were then incubated with a secondary antibody, goat anti-rabbit IgG coupled to rhodamine. All pictures were obtained with identical camera and computer settings. In contrast to Fig. 1, no increase in fluorescence was seen in lung sections incubated with the NTAb as compared to IgG. Results were reproduced using either formalin-fixed, or fresh-frozen sections from five patients who did not show evidence of acute lung injury at death.

obtained when tissues were immunostained with either the $\mathrm{NTAb}$ or an equivalent amount of nonimmune IgG.

For each patient, values for the various fields in each section (at least $n=4$ ) were averaged and the mean value was used to calculate the group mean (Fig. 4). Thus, each patient was weighed equally in the calculation of the group mean. These results indicate that the lungs of patients with clinical and pathologic ARDS, but not from lungs without evidence of acute or chronic inflammation, contained significant levels of residues antigenically related to nitrotyrosine. In all lung sections obtained from ARDS patients, incubated with the NTAb in the presence of excess antigen ( $10 \mathrm{mM}$ nitrotyrosine), fluorescence levels returned to control levels. Thus each patient served as its own control and the data indicate the presence of residues antigenically related to nitrotyrosine in the lungs of all ARDS patients examined, but in none of the controls.

Fresh-frozen lung sections from rats that were exposed to $100 \% \mathrm{O}_{2}$ for $60 \mathrm{~h}$, which results in a form of lung injury that has many of the characteristics of human ARDS (11), exhibited significantly higher levels of immunostaining when incubated with the NTAb (Fig. 5). Similar to the lung sections of patients with severe acute lung injury, immunostaining was totally absent when lung sections were incubated with both the polyclonal antibody in the presence of nitrotyrosine $(10 \mathrm{mM})$, or with an equivalent amount of nonimmune IgG (Fig. 5). Mean fluorescence values for the hyperoxic and control groups are shown in Fig. 6. Data shown in this figure indicate the presence of residues antigenically related to nitrotyrosine in the lungs of rats exposed to hyperoxia. Significant levels of nitrotyrosine were also demonstrated in lung sections incubated with added peroxynitrite ( $1 \mathrm{mM}$; Fig. 7), but not hydrogen peroxide, superoxide anions, and hydroxyl radicals, generated by the action of xanthine oxidase $(10 \mathrm{mM})$ on pterin $(200 \mu \mathrm{M}$; not shown $)$, or -NO alone, generated by SNAP ( $100 \mu \mathrm{M}$ plus $100 \mu \mathrm{M}$ L-cysteine) or SNAP alone (1 mM; data not shown $)$.

\section{Discussion}

Peroxynitrite, a potent oxidant generated from the rapid reaction of NO with superoxide, has been implicated in the initiation and propagation of oxidant lung injury (14). However, in vivo generation of peroxynitrite has not previously been demonstrated in the lungs. Peroxynitrite, but not $\bullet \mathrm{NO}$ or superoxide, is capable of nitrating phenolic rings and tyrosine residues of proteins $(10,15)$. Using immunofluorescent techniques, we have quantified nitrotyrosine residues in the lungs of both animals and humans. Acute lung inflammation during ARDS, triggered by a variety of predisposing factors, was associated with increased nitrotyrosine levels. Immunofluorescence was uniform across the disrupted epithelial-capillary membrane. Also, immunostaining was specific, since it was blocked completely by an excess amount of nitrotyrosine. Beckman et al. (12) have shown that the NTAb did not cross-react with bovine serum albumin that has been previously treated with $5 \mathrm{mM}$ hypochlo- 


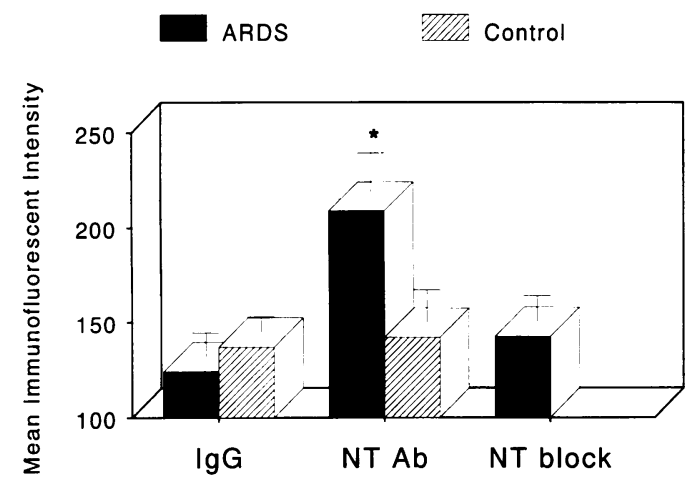

Figure 4. Quantification of immunofluorescent intensity of semi-thin (4-6 $\mu \mathrm{m}$ ) lung sections, obtained from patients who died either with ARDS or non-pulmonary causes. For each patient, fresh-frozen or paraffin-embedded sections were incubated with $(a)$ nonspecific $\operatorname{IgG}(\operatorname{IgG})$ (b) an equivalent amount of the polyclonal antibody to nitrotyrosine (NTAb); or $(c)$ with the NTAb in the presence of $10 \mathrm{mM}$ nitrotyrosine, followed by the secondary antibody (goat anti-rabbit IgG coupled to rhodamine). For each patient and each condition, values for the various images (at least $n=4$ ) were averaged and the mean value was used to calculate the group mean (five patients in each group; see text for details). All pictures were obtained with identical camera and computer settings. Sections from ARDS lungs incubated with the NTAb exhibited approximately two times the fluorescence of those incubated with nonimmune IgG or sections of control lungs incubated with the NTAb. Values are means \pm SEM. $* p<0.05$ compared with corresponding IgG value in the same patient population.

rous acid or xanthine oxidase plus $\mathrm{Fe}^{3+}$ EDTA. Also, incubation of peroxynitrite-treated surfactant protein A with dithionite, which reduces nitrotyrosine to aminotyrosine, completely eliminates the NTAb binding to this protein (10).

ARDS is characterized by increased endothelial and epithelial permeability, mediated by persistent release of inflammatory cytokines and various oxidants $(16,17)$. In support of the oxidant stress theory is the protection demonstrated by administration of antioxidants in humans or animal models of ARDS (18, 19). However, the exact nature of the in vivo oxidants remains in dispute. Alveolar macrophages, endothelial, and type II epithelial cells synthesize $\cdot N O$ via oxidative deamination of $\mathrm{L}$ arginine, and superoxide via a membrane bound NADPH oxidase $(20,21)$. Although basal levels of $\bullet$ NO may be low, expo-

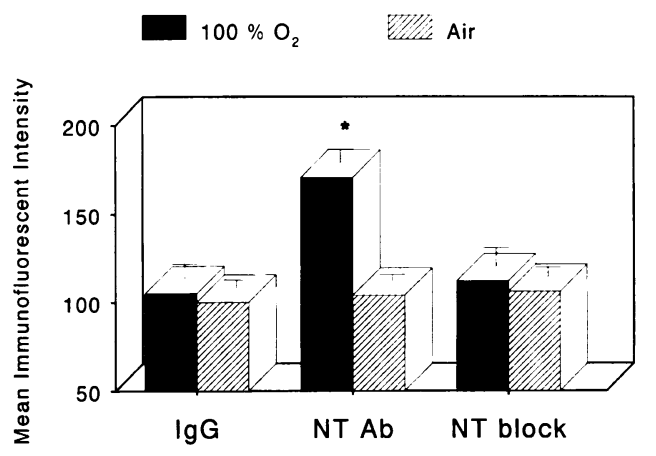

Figure 6. Quantification of immunofluorescent intensity of semi-thin (4-6 $\mu \mathrm{m}$ ), frozen sections, obtained from the lungs of rats that breathed either oxygen ( $100 \% \mathrm{O}_{2}$ for $60 \mathrm{~h} ; n=4$ ) or room air (unexposed; $n$ $=4$ ). For each rat, lung sections were incubated with $(a)$ nonspecific IgG (IgG); $(b)$ an equivalent amount of the polyclonal antibody to nitrotyrosine (NTAb); or $(c)$ with the NTAb in the presence of $10 \mathrm{mM}$ nitrotyrosine, followed by the secondary antibody (goat anti-rabbit IgG coupled to rhodamine). For each rat and each condition, values for the various images (at least $n=4$ ) were averaged and the mean value was used to calculate the group means. All pictures were obtained with identical camera and computer settings. Sections from hyperoxic rat lungs incubated with the NTAb exhibited approximately two times the fluorescence intensity of those incubated with nonimmune IgG or NTAb in the presence of $10 \mathrm{mM}$ nitrotyrosine. Values are means \pm SEM. ${ }^{*} p$ $<0.05$ compared with corresponding IgG within the same group.

sure of these cells to diverse stimuli of inflammation such as lipopolysaccharide (LPS), and interferon- $\gamma$ generate large amounts of $\bullet \mathrm{NO}$ for prolonged periods of time $(22,23)$. In addition, superoxide production is increased in ARDS particularly during periods of increased exogenous oxygen administration (24). $\bullet$ NO reacts with superoxide at a rate constant of 6.7 $\times 10^{9} \mathrm{M}^{-1} \mathrm{~s}^{-1}$ at $\mathrm{pH} 7.4$ to form peroxynitrite (25). At physio$\operatorname{logic} \mathrm{pH}$, peroxynitrite can directly nitrate phenolic rings by a reaction with an activation energy of $20 \mathrm{kcal} \times \mathrm{mol}^{-1}$ or undergo a metal ion-catalyzed reaction to form a potent nitrating agent resembling the nitronium ion (26).

However, peroxynitrite may not be the only species capable of tyrosine nitration. Nitrogen dioxide can also nitrate tyrosine, although it is much less efficient than peroxynitrite because two molecules of nitrogen dioxides are required to nitrate one

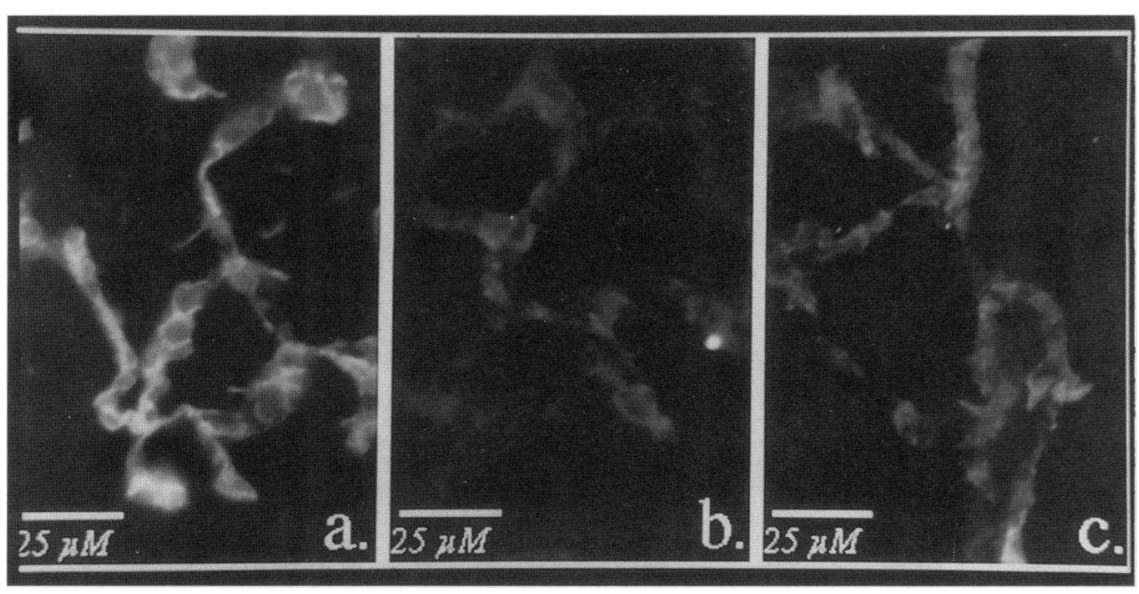

Figure 5. Epifluorescence images of frozen, semi-thin $(4-6 \mu \mathrm{m})$ sections of lungs from rats that were exposed to $100 \% \mathrm{O}_{2}$ for $60 \mathrm{~h}$ ( $a$ and $b$ ) or room air $(c)$. Sections $a$ and $c$ were immunostained with the polyclonal antibody to nitrotyrosine (NTAb); section $b$, with an equivalent amount of nonimmune IgG. All sections were then incubated with a secondary antibody, goat anti-rabbit IgG coupled to rhodamine. All pictures were obtained with identical camera and computer settings. Notice the significantly higher level of fluorescence when an oxygen exposed lung section was incubated with the NTAb as compared to a room air control. Typical sections were reproduced using lung sections from four different oxygen and three air breathing rats. 

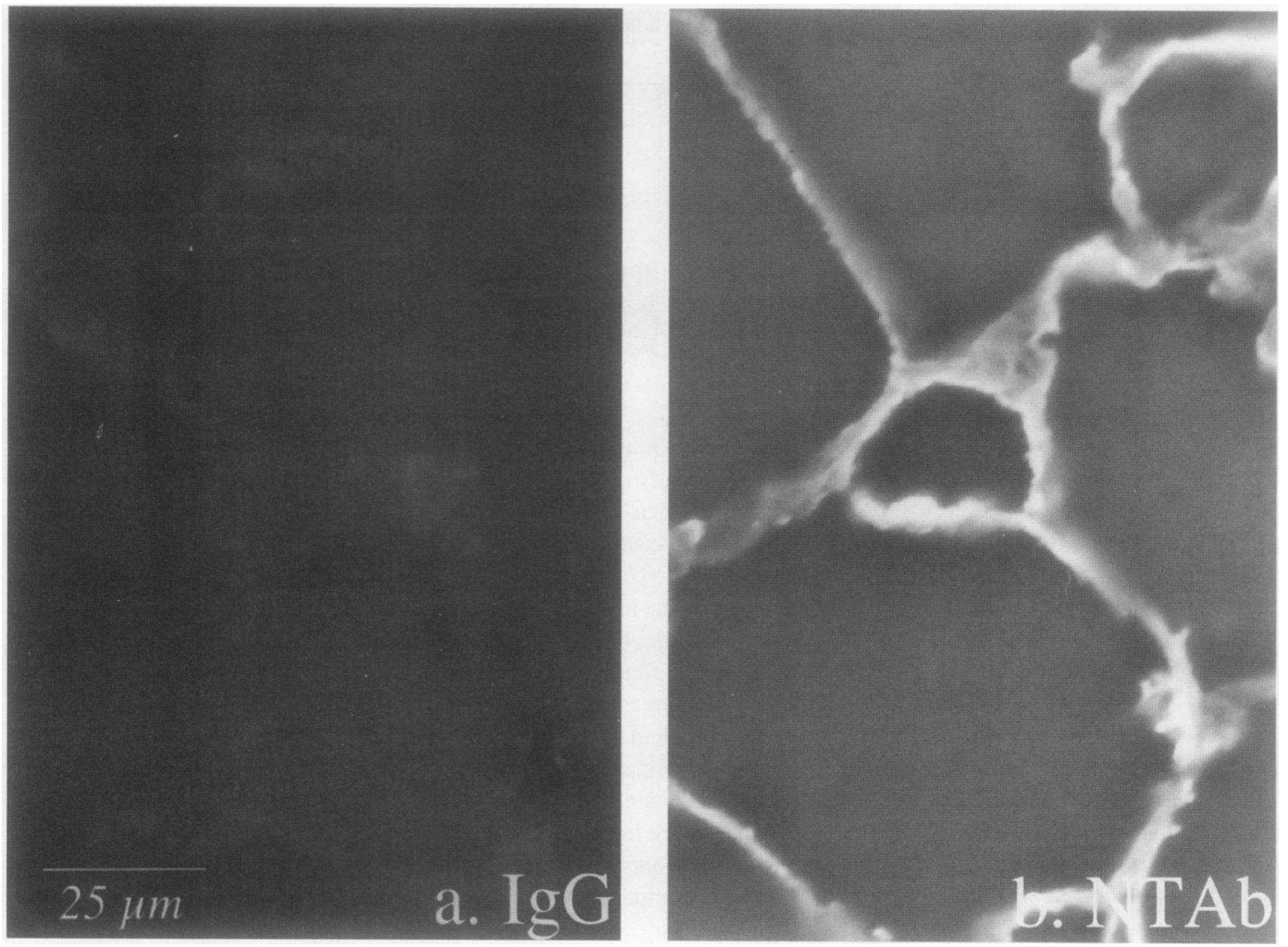

Figure 7. Epifluorescence images of semi-thin $(4-6 \mu \mathrm{m})$, frozen rat lung sections. Sections were exposed to $1 \mathrm{mM}$ peroxynitrite for $15 \mathrm{~min}$, by immersion in a $10 \mathrm{mM}$ Hepes solution ( $\mathrm{pH} 7.4)$ to which peroxynitrite was added at time zero. They were then immunostained with either the polyclonal antibody to nitrotyrosine (NTAb; right), or an equivalent amount of nonspecific IgG (IgG; left), followed by the secondary antibody, goat anti-rabbit IgG conjugated to rhodamine. White areas contain higher fluorescence than background (black). Exposures were taken under identical conditions. Typical images were reproduced at least four times.

tyrosine (12). This will result in a slow overall nitration rate by nitrogen dioxide. We have shown that the NTAb did not cross-react with rat lung sections exposed to reactive oxygen species generated by xanthine oxidase plus $\mathrm{Fe}^{3+} \mathrm{EDTA}$, or to -NO generated by SNAP (100 $\mu \mathrm{M}$ plus $100 \mu \mathrm{M}$ L-cysteine) This amount of SNAP has been shown to generate $\cdot N O$ at a mean concentration of $1 \mu \mathrm{M} \cdot \mathrm{NO}$ over the 2 -h exposure time (10). It should be noted that at these physiologic low concentrations of $\cdot \mathrm{NO}$, nitrogen dioxide formation from the reaction of $\bullet \mathrm{NO}$ and dioxygen will be extremely slow and can be ignored (12).

Several methods have been used to detect the presence of nitrotyrosine. Nitrotyrosine content can be quantified by HPLC analysis of amine-derivatized free amino acids following hydrolysis in $6 \mathrm{~N} \mathrm{HCl}$ for $16-24 \mathrm{~h}$ at $100^{\circ} \mathrm{C}(8)$. Nitrotyrosine has recently been found in the urine of healthy humans by a sensitive gas chromatographic-thermal energy analysis method (27), in atherosclerotic lesions of formalin-fixed human coronary arteries, and in lung sections of patients with sepsis-induced ARDS and pneumonia (28). Furthermore, detection of nitrated tyrosine residues by the NTAb in peroxynitrite-treated bovine serum albumin correlated with quantitation using a modified HPLC which relies on the intrinsic ultraviolet (UV) absorbance of nitrotyrosine at $280 \mathrm{~nm}(29)$.

Although activated rat alveolar macrophages produce $\bullet \mathrm{NO}$ and peroxynitrite (22), the production of these species by isolated human macrophages stimulated by various cytokine combinations has been more difficult to demonstrate (30). Denis
(31) has described the induction of high-output $\bullet$ NO synthase by human blood monocyte-derived macrophages infected with Mycobacterium avium. Also, Pneumocystis carinii, but not a combination of lipopolysaccharide and interferon- $\gamma$, increased nitrite production by isolated human lung macrophages (32), suggesting that these cells are capable of $\bullet \mathrm{NO}$ generation when properly stimulated. Recently, Kobzik et al. (20) demonstrated that human alveolar macrophages immunostain for inducible -NO synthase in areas of inflammation.

Tyrosine nitration may have a biologic effect on the structure and function of proteins. Nitration of surfactant protein A by peroxynitrite has been associated with decreased protein function (8). Similarly, nitration of tyrosine inhibits cytochrome P450 (33) and inactivates the complement subcomponent Clq binding capacity of human IgG (34). Tyrosine nitration has also been shown to inhibit protein phosphorylation, which may interfere with intracellular signal transduction (35). Nitrotyrosine, increased in subject J. J. during an episode of ARDS, was at baseline levels in lung sections obtained from this patient during an open lung biopsy, $\sim 1$ yr later. This suggests that nitrotyrosine can be turned over and degraded in vivo. However, the rate of turnover and the mechanism involved remain to be determined.

\section{Acknowledgments}

The authors would like to acknowledge the excellent technical assistance of C. T. Myles and the editorial assistance of Ms. A. Kornegay. 
This project was supported by a Child Health Research Center grant to Children's Hospital of Alabama, National Institutes of Health grants HL-31197, HL-51173, 5PO1 HL-48676 and a grant from the Office of Naval Research (000014-93-0785). Dr. Beckman is an Established Investigator of the American Heart Association.

\section{References}

1. Kinsella, J. P., S. R. Neish, E. Shaffer, and S. H. Abman. 1992. Low-dose inhalational nitric oxide in persistent pulmonary hypertension of the newborn. Lancet (N. Am. Ed.). 340:819-820.

2. Rossaint, R., K. J. Falke, F. Lopez, K. Slama, U. Pison, and W. M. Zapol. 1993. Inhaled nitric oxide for the Adult Respiratory Distress Syndrome. N. Engl. J. Med. 328:399-405.

3. Kwon, N. S., D. H. Stuehr, and C. F. Nathan. 1991. Inhibition of tumor cell ribonucleotide reductase by macrophage-derived nitric oxide. J. Exp. Med. 174:761-767.

4. Stadler, J., T. R. Billiar, R. D. Curran, D. J. Stuehr, J. B. Ochoa, and R. L. Simmons. 1991. Effect of exogenous and endogenous nitric oxide on mitochondrial respiration of rat hepatocytes. Am. J. Physiol. 620:C910-C916.

5. Radi, R., J. S. Beckman, K. M. Bush, and B. A. Freeman. 1991. Peroxynitrite oxidation of sulfhydryls. J. Biol. Chem. 266:4244-4250.

6. Radi, R., J. S. Beckman, K. M. Bush, and B. A. Freeman. 1991. Peroxynitrite-induced membrane lipid peroxidation: The cytotoxic potential of superoxide and nitric oxide. Arch. Biochem. Biophys. 288:484-487.

7. Beckman, J. S., T. W. Beckman, J. Chen, P. A. Marshall, and B. A. Freeman. 1990. Apparent hydroxyl radical production by peroxynitrite: Implications for endothelial injury from nitric oxide and superoxide. Proc. Natl. Acad. Sci. USA. 87:1620-1624.

8. Haddad, I. Y., H. Ischiropoulos, B. A. Holm, J. S. Beckman, J. R. Baker, and S. Matalon. 1993. Mechanisms of peroxynitrite induced injury to pulmonary surfactant. Am. J. Physiol. 265 (Lung Cell Mol. Physiol. 9):L555-L564.

9. Hu, P., H. Ischiropoulous, J. S. Beckman, and S. Matalon. 1994. Peroxynitrite inhibition of oxygen consumption and ion transport in alveolar type II cells. Am. J. Physiol. 266 (Lung Cell Mol. Physiol. 10):L628-L634.

10. Haddad, I. Y., J. Crow, Y. Yoazu, J. S. Beckman, and S. Matalon. 1994. Concurrent generation of nitric oxide and superoxide damages surfactant protein A (SP-A). Am. J. Physiol. 267 (Lung Cell Mol. Physiol. 11):L242-L249.

11. Crapo, J. D., B. E. Barry, H. A. Foscue, and J. Shelburne. 1980. Structural and biochemical changes in rat lungs occurring during exposures to lethal and adaptive doses of oxygen. Am. Rev. Respir. Dis. 122:123-143.

12. Beckman, J. S., Y. Z. Ye, P. Anderson, J. Chen, M., Accavitti, M. M. Tarpey, and C. R. White. 1994. Extensive nitration of protein tyrosines in human atherosclerosis detected by immunohistochemistry. Biol. Chem. Hoppe-Seyler. 375:81-88.

13. Matalon, S., K. L. Kirk, J. K. Bubien, Y. Oh, P. Hu, G. Yue, R. Shoemaker, E. J. Cragoe, Jr., and D. J. Benos. 1992. Immunocytochemical and functional characterization of $\mathrm{Na}^{+}$conductance in adult alveolar pneumocytes. Am. J. Physiol. 262 (Cell Physiol. 31): C1228-C1238.

14. Mulligan, M. S., J. M. Hevel, M. A. Marletta, and P. A. Ward. 1991. Tissue injury caused by deposition of immune complexes is L-arginine dependent. Proc. Natl. Acad. Sci. USA. 88:6338-6342.

15. Ischiropoulos, H., L. Zhu, J. Chen, M. Tsai, J. C. Martin, C. D. Smith, and J. S. Beckman. 1992. Peroxynitrite-mediated tyrosine nitration catalyzed by superoxide dismutase. Arch. Biochem. Biophys. 298:431-437.

16. Cochrane, C. G., R. Spragg, and S. D. Revak. 1983. Pathogenesis of the adult respiratory distress syndrome: evidence of oxidant activity in bronchoalveolar lavage fluid. J. Clin. Invest. 71:754-761.
17. Donnelly, T. J., P. Meade, M. Jaggels, H. G. Cryer, M. M. Law, T. E Hugli, W. C. Shoemaker, and E. Abraham. 1994. Cytokine, complement, and endotoxin profiles associated with the development of the adult respiratory distress syndrome after severe injury. Crit. Care Med. 22:768-776.

18. Suter, P. M., G. Domenighetti, M.-D. Schaller, M.-C. Laverriere, R. Ritz, and C. Perret. 1994. $\mathrm{N}$-acetylcysteine enhances recovery from acute lung injury in man. Chest. 105:190-194.

19. Padmanabhan, R. V., R. Gudapaty, I. E. Liener, B. A. Schwartz, and J. R. Hoidal. 1985. Protection against pulmonary oxygen toxicity in rats by the intratracheal administration of liposome-encapsulated superoxide dismutase or catalase. Am. Rev. Respir. Dis. 132:164-167.

20. Kobzik, L., D. S. Bredt, C. J. Lowenstein, J. Drazen, B. Gaston, D. Sugarbaker, and J. Stamler. 1993. Nitric oxide synthase in human and rat lung: Immunocytochemical and histochemical localization. Am. J. Respir. Cell Mol. Biol. 9:371-377.

21. Moncada, S., and E. A. Higgs. 1991. Endogenous nitric oxide: Physiology, pathology, and clinical relevance. Eur. J. Clin. Invest. 21:361-374.

22. Ischiropoulos, H., L. Zhu, and J. S. Beckman. 1992. Peroxynitrite formation from macrophage-derived nitric oxide. Arch. Biochem. Biophys. 298:446451.

23. Munoz-Fernadez M. A., M. A. Fernadez, and M. Fresno. 1992. Synergism between tumor necrosis factor- $\alpha$ and interferon- $\gamma$ on macrophage activation for the killing of intracellular Trypanosoma cruzi through a nitric oxide-dependent mechanism. Eur. J. Immunol. 22:301-307.

24. Turrens J. F., B. A. Freeman, J. G. Levitt, and J. D. Crapo. 1982. The effect of hyperoxia on superoxide production by lung submitochondrial particles. Arch. Biochem. Biophys. 217:401-410.

25. Huie, R. E., and S. Padmaja. 1993. Reaction of nitric oxide with superoxide. Free Radical Res. Commun. 18:195-199.

26. Beckman, J. S., H. Ischiropoulos, L. Zhu, M. van der Woerd, C. Smith, J. Chen, J. Harrison, J. C. Martin, and M. Tsai. 1992. Kinetics of superoxide dismutase-and iron-catalyzed nitration of phenolics by peroxynitrite. Arch. Biochem. Biophys. 298:438-445.

27. Ohshima, H., M. Friesen, I. Brouet, and H. Bartsch. 1990. Nitrotyrosine as a new marker for endogenous nitrosylation and nitration of proteins. Fundamen. Chem. Toxicol. 28:647-652.

28. Kooy, N. W., J. A. Royall, Y. Z. Ye, D. R. Kelly, and J. S. Beckman 1994. Peroxynitrite is produced during human adult respiratory distress syndrome. Am. Rev. Respir. Dis. 149:A814. (Abstr.)

29. Crow, J. P., and J. S. Beckman. 1994. Quantitation of protein tyrosine, 3 nitrotyrosine, and 3-aminotyrosine utilizing HPLC and intrinsic UV absorbance. Methods (Orlando). In press.

30. Padgett, E. L., and S. B. Pruett. 1992. Evaluation of nitrite production by human monocyte-derived macrophages. Biochem. Biophys. Res. Commun. 186:775-781.

31. Denis, M. 1991. Tumor necrosis factor and granulocyte macrophagecolony stimulating factor stimulate human macrophages to restrict growth of virulent Mycobacterium avium and to kill avirulent $\boldsymbol{M}$. avium: Killing effector mechanism depends on the generation of reactive nitrogen intermediates. J. Leukocyte Biol. 49:380-387.

32. Sherman, M. P., M. L. Loro, V. Z. Wong, and D. P. Tashkin. 1991 Cytokine-and Pneumocystis carinii-induced L-arginine oxidation by maurine and human pulmonary alveolar macrophages. J. Protozool. 38:234S-236S.

33. Janing, G. R., R. Kraft, J. Blank, O. Ristau, H. Rabe, and K. Ruckpaul. 1987. Chemical modification of cytochrome P-450 LM4. Identification of functionally linked tyrosine residues. Biochim. Biophys. Acta. 916:512-523.

34. McCall, M. N., and S. B. Easterbrook-Smith. 1989. Comparison of the role of tyrosine residues in human IgG and rabbit IgG in binding of complement subcomponent C1q. Biochem. J. 257:845-851.

35. Martin, B. L., D. Wu, S. Jakes, and D. J. Graves. 1990. Chemical influences on the specificity of tyrosine phosphorylation. J. Biol. Chem. 265:7108-7111. 